\title{
ASSOCIATION OF OBESITY WITH HYPERTENSION IN ADULT FEMALE
}

\author{
NAHID YEASMIN ${ }^{1}$, SAYEEDA MAHMUDA ${ }^{2}$, SHAMIMA AKTHER, ${ }^{3}$ KHADIJA BEGUM ${ }^{4}$, MASUD SALEHIN ${ }^{5}$ \\ SULTANA YEASMIN ${ }^{6}$
}

\begin{abstract}
Background: Incidence of hypertension in female is increasing throughout the world, leading to life threatening medical problem like cardiovascular diseases, stroke. An association between hypertension and obesity has been identified. Objectives : The study was carried out to observe the association of obesity with hypertension in adult female. Methods : This cross sectional study was conducted in the Department of Physiology, Dhaka Medical College, Dhaka, during the period of January 2011 to December 2011. A total number of one hundred female subjects were selected with age ranging from 30 to50 years. Among them 50 hypertensive female subjects were included from out-patient department of Medicine, Dhaka medical college Hospital, Dhaka as study group(B) and 50 apparently healthy female were taken as control group(A) for comparison Waist circumference(WC) was measured and body mass index (BMI) was calculated in both groups. Data was analyzed by Unpaired Student's ' $t$ ' test and Pearson's correlation co-efficient (r) test as applicable. Results: The value of waist circumference was higher in hypertensive subjects than those of nonhypertensive female and result was statistically significant. Body mass index value was significantly $(p<0.001)$ higher in hypertensive subjects in comparison to those of non-hypertensive subjects. In hypertensive subjects waist circumference and body mass index values were higher and showed significant positive correlation with systolic and diastolic blood pressure. Conclusion: Present study revealed that hypertension has positive and significant relationship with waist circumference and body mass index.
\end{abstract}

Key words: Waist circumference, body mass index, hypertension.

\section{Introduction}

The prevalence of hypertension is increasing throughout the world. Hypertension is a major public problem in many parts of the world. ${ }^{1}$ It is known as "the silent killer", it may exit for prolonged periods without symptoms and may manifest only after causing serious complications ${ }^{2}$. Hypertension is a recognized modifiable risk factor of cardiovascular disease, stroke and end stage renal disease. The prevalence of hypertension has increased in women than man. It is considered as the leading cause of morbidity and mortality in the modern world ${ }^{3}$

It has been identified as the most common, most potent and most universal contributor to cardiovascular mortality, which accounts for $20-50 \%$ of all deaths. ${ }^{2}$
According to global estimates, in 2000, 972 million adult had hypertension and it is predicted to rise by to $60 \%$ to a total 1.56 billion by $2025^{.4}$ Overweight and obesity are important risk factors for hypertension and hypertension is approximately twice as prevalent in the obese than non obese ${ }^{5}$

Obesity results from abnormal accumulation of fat deposits, which consists of an excessive storage of triacylglycerol within adipocytes located in subcutaneous tissue and intra-abdominal viscera. ${ }^{6}$ Currently about 1.5 billion people in the world are overweight. About 200 million men and 300 million women are obese. More than one in ten of the world's adult population is obese. Overweight and obesity are the fifth leading risk for global deaths, with at least 2.8 million adult dying annually as a result of

1. Assistant Professor, Department of Physiology, Dhaka Medical College, Dhaka

2. Associate Professor (CC), Department of Pathology ,National Institute of Ophthalmology \& Hospital, Sher-E-Bangla Nagar, Dhaka.

3. Assistant Professor, Department of Physiology, Dhaka Medical College, Dhaka

4. Assistant Professor, Department of Physiology,, Ad-din Women's Medical College, Dhaka

5. Mphil student (thesis part) Department of Physiology, Dhaka medical College.

6. Assistant professor, (CC) Department of Pharmacology, Dhaka Medical College.

Bangladesh J Medicine 2017; $28: 28-33$ 
obesity ${ }^{7}$. Obesity has been associated with chronic non-communicable diseases like hypertension, coronary heart disease, type 2 diabetes, dyslipidemia, chronic kidney disease, cancer and arthritis. ${ }^{8}$

A number of studies have shown the risk of obesity increases the hypertension .In the Framingham study, a $10 \%$ rise in body weight is associated with a $7 \mathrm{mmhg}$ rise systolic blood pressure ${ }^{9}$ The National Health and Nutrition Examination survey reported linear association between increase in body mass index and systolic, diastolic and pulse pressure in the American population. It is reported that an increase of body mass index of a $1.75 \mathrm{~kg} / \mathrm{m} 2$ in men and $1.25 \mathrm{~kg} / \mathrm{m} 2$ in women will cause $1 \mathrm{~mm} \mathrm{Hg}$ rise in systolic blood pressure. ${ }^{10}$

Again some studies have shown that weight reduction through diet and regular physical exercise has been associated with reduction in blood pressure. It has been shown that only $5 \%$ weight loss is associated with reduction in blood pressure in hypertensive patient. 11

Obesity has been recognized as a most important risk factor for developing hypertension. Several epidemiological studies from different populations have been reported a significant association between obesity and hypertension. The link between obesity and hypertension is though neuroendocrine mechanisms and most recently, factors derived from adipose tissue are thought to play a major role ${ }^{12}$

Obesity lead to hypertension and other cardiovascular diseases by activating the renin- angiotensinaldosterone system, thus increasing sympathetic activities and enhancing insulin and leptin resistance with increased procoagulatory activites ${ }^{12}, .{ }^{13}$

Some other study reported that greater increased in waist circumference and body mass index in hypertensive subjects than that of controls.1,2,6, Opposite finding was reported by some investigators who did not find any significant difference in body mass index value in hypertensive subjects and controls $^{4}$

Some studies have been done on this regard in abroad but no published data has yet been available on this aspect in our country. Therefore, the present study has been designed to observe the effect of obesity in hypertension. Better understanding of these metabolic changes with obesity in hypertensive patient will help in the detection of women at risk for future cardiovascular diseases. Treatment and preventive measure can reduce the risk of developing cardiovascular diseases and thus reduce burden on our health budget.

\section{Methods}

This cross sectional study was conducted in the Department of Physiology, Dhaka Medical College, Dhaka, during the period of January 2011 to December
2011. Fifty female of 30-50 years of age with hypertension participated in this study as study (B) group. They were selected from out- patient department of Medicine, Dhaka Medical College Hospital; Dhaka. Age matched fifty apparently healthy females studied as control(A) group for comparison. Subjects having history of heart, liver, kidney diseases, endocrine disorders and women taking hormone replacement therapy, steroid, alcohol user, smoker were excluded from the study. After selection of the subjects, the objectives, nature, purpose and benefit of the study were explained to the subjects in details. Ethical permission was taken from ethical committee of Dhaka Medical College. After selection of subjects, the objective, nature, purpose and benefit of the study were explained to the subjects in details. Written informed consents were taken from the participants. The subjects were advised to attend the laboratory in the department of Physiology of Dhaka Medical College, Dhaka between 8AM to 10AM. Detailed personal history, medical history, drugs history, family history and all the clinical examinations were done. Then waist circumference was measured with a soft non elastic measuring tape. It is the horizontal circumference was taken in a standing position between the lower border of the $12^{\text {th }}$ rib and highest point of the iliac crest on the mid axillary line at the end of normal expiration. Height was measured using a stadiometer without shoes and weight was taken with light clothing on the nearest $0.5 \mathrm{~kg}$. Body mass index (BMI) was determined based on the formula weight in $\mathrm{kg} /$ height in meters squared in both groups to observe their status of obesity. BMI was classified using the WHO classification for adult as follows: normal for values in the range of $18.5-25 \mathrm{~kg} / \mathrm{m} 2$, overweight BMI 25 and $-29.9 \mathrm{~kg} / \mathrm{m} 2$, class 1 obesity BMI 30 to $34.9 \mathrm{~kg} /$ $\mathrm{m} 2$, class II 35.0 to $39.9 \mathrm{~kg} / \mathrm{m} 2$ class III or extreme obesity $\mathrm{BMI}>40 \mathrm{~kg} / \mathrm{m} 2 .{ }^{13}$ Moreover, waist circumferences $>88 \mathrm{~cm}$ in female and $>102 \mathrm{~cm}$ in male are the cut point for obesity. 14

The blood pressure of the subjects was measured after 5 minutes rest with a sphygmomanometer using an appropriate cuff size in the right arm ${ }^{15}$ Hypertension was defined according to the Joint National Committee (JNC) VII criteria. ${ }^{16}$ Statistical analysis was done by Unpaired Student's 't' test. Correlation was analyzed by Pearson's correlation coefficient $(r)$ test. $P$ value $<0.05$ was taken as of significance.

\section{Results}

The value of mean waist circumference of hypertensive subject was significantly higher than that of controls. The mean body mass index was also higher in hypertensive subjects and result was statistically significant $(\mathrm{p}<0.001)$. 
Table I

Age, Systolic blood pressure (SBP) and diastolic blood pressure $(D B P)$ in both group

\begin{tabular}{ccccc}
\hline Groups & $\mathrm{n}$ & Age (years) & $\mathrm{SBP}(\mathrm{mmHg})$ & $\mathrm{DBP}(\mathrm{mmHg})$ \\
\hline & & $($ Mean $\pm \mathrm{SD})$ & $($ Mean \pm SD) & $($ Mean $\pm \mathrm{SD})$ \\
$\mathrm{A}$ & 50 & $28.77 \pm 6.66$ & $115.03 \pm .15$ & $74 \pm .77$ \\
$\mathrm{~B}$ & 50 & $29.90 \pm 5.75$ & $140.13 \pm .21$ & $89.72 \pm 4.35$ \\
\hline
\end{tabular}

Statistical analysis

\begin{tabular}{lccc}
\hline Groups & Age & WC & BMI \\
\hline ( $\mathrm{p}$ value) & (p value) & (pvalue) & \\
A vs B & $0.0001^{* * *}$ & $0.0001^{* * *}$ & $0.0001^{* * *}$ \\
\hline
\end{tabular}

$\mathrm{WC}=$ Waist circumfernece, $\mathrm{BMI}=$ Body mass index Unpaired Student's 't' test was performed to compare between groups. The test of significance was calculated and $\mathrm{p}$ values $<0.05$ was accepted as level of significance.

Group A : Healthy adult female $\mathrm{n}=$ Number of subjects Group B : Hypertensive female $\mathrm{ns}=$ Not significant

$* * *=$ Significant at $\mathrm{P}<0.001$

Mean values of systolic and diastolic blood pressure were higher in hypertensive subjects than that of controls and results were statistically significant. Table-II.

Table-II

Waist circumference and body mass index values in both groups

\begin{tabular}{ccc}
\hline & \multicolumn{2}{c}{ Hypertensive } \\
\cline { 2 - 3 } Parameters & Control & patient \\
\hline Waist circumference & $76.69 \pm 3.61$ & $90.69 \pm 6.13$. \\
Body mass index & $22.60 \pm 3.00$ & $30.50 \pm 4.35$ \\
\hline
\end{tabular}

\section{Results are expressed as mean \pm SD}

Unpaired Student's 't' test was performed to compare between groups. The test of significance was calculated and $\mathrm{p}$ values $<0.05$ was accepted as level of significance.

Group A : Adult healthy female

Group B : Hypertensive female

Again Distribution of parameters were observed in hypertensive subjects and $38.3 \%$ had waist circumference within normal level whereas, $62.7 \%$ had above normal level (i.e >85 cm). Again, $36.7 \%$ of hypertensive subjects had body mass index within normal level whereas, $64.3 \%$ had above normal level (i.e $>30 \mathrm{~kg} / \mathrm{m}^{2}$ ). Table III.
Table-III

Distribution of the subjects by the study parameters in hypertensive female

\begin{tabular}{lcc}
\hline Parameters & \multicolumn{2}{c}{ Group B( $\mathrm{n}=50)$} \\
\cline { 2 - 3 } & No. & $(\%)$ \\
\hline Waist circumference $(\mathrm{cm})$ & & $(38.3)$ \\
$<85$ & 19 & $(62.7)$ \\
$>85$ & 31 & \\
Body mass index $\left(\mathrm{kg} / \mathrm{m}^{2}\right)$ & & $(24.7)$ \\
$25-30$ & 12 & $(76.3)-$ \\
$>30$ & 38 & \\
\hline
\end{tabular}

$\mathrm{N}=$ Number of subjects

Group B: Study group (adult hypertensive female)

Systolic blood pressure showed positive correlation with waist circumference and body mass index in hypertensive subjects. Table- IV and Figure-1,2.

Again, diastolic blood pressure also showed positive correlation with waist circumference and body mass index in hypertensive subjects. Table- $\mathrm{V}$ and Figure 3 and-V.

\section{Table-IV}

Correlation of Systolic blood pressure with WC and BMI in hypertensive female

\begin{tabular}{lcc}
\hline Parameters & \multicolumn{2}{c}{ Group B (n=60) } \\
\cline { 2 - 3 } & $\mathrm{r}$ & $\mathrm{p}$ \\
\hline Waist circumference (WC) & +0.820 & 0.001 \\
Body mass index (BMI) & +0.038 & 0.804 \\
\hline
\end{tabular}

Pearson's correlation coefficient (r) test was performed to compare relationship between parameters. The test of significance was calculated and $p$ value $<0.05$ was accepted as level of significance.

Table V

Correlation of Diastolic blood pressure with WC and BMI in hypertensive female

\begin{tabular}{lcc}
\hline Parameters & \multicolumn{2}{c}{ Group B $(\mathrm{n}=50)$} \\
& $\mathrm{r}$ & $\mathrm{p}$ \\
\hline Waist circumference (WC) & +0.399 & 0.004 \\
Body mass index (BMI) & +0.034 & 0.817 \\
\hline
\end{tabular}

Pearson's correlation coefficient (r) test was performed to compare relationship between parameters. The test of significance was calculated and $p$ value $<0.05$ was accepted as level of Significance. 
BJM Vol. 28 No. 1

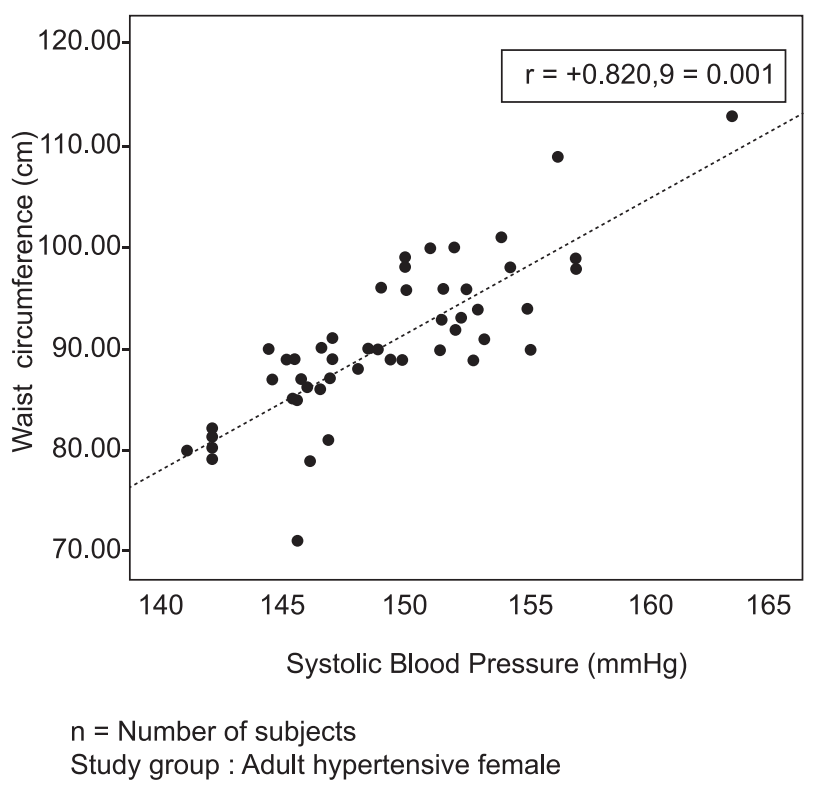

Fig.-1: Correlation between systolic blood pressure and waist circumference in study group $(n=50)$.

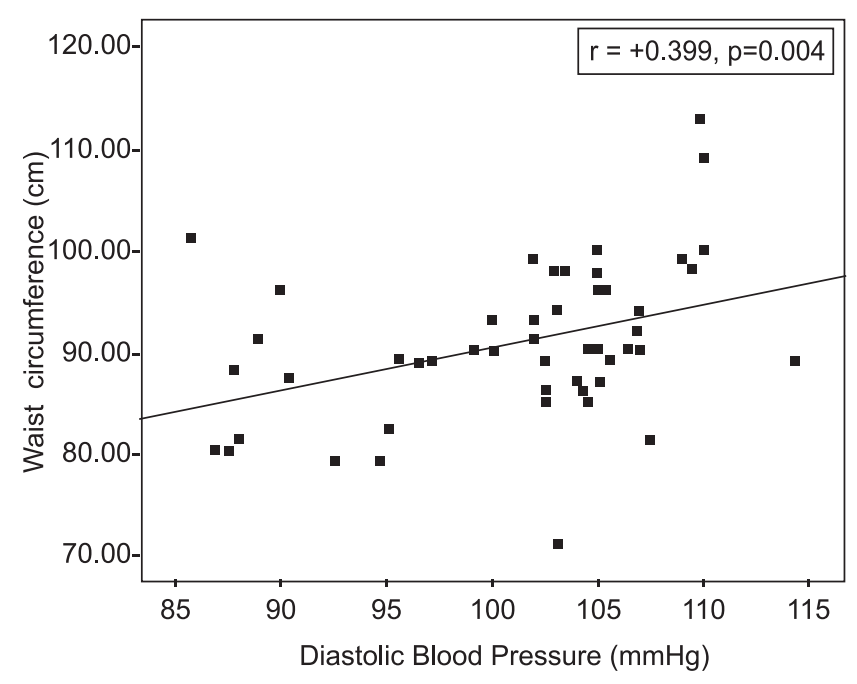

$\mathrm{n}=$ Number of subjects

Study group : Adult hypertensive female

Fig.-3: Correlation between diastolic blood pressure and waist circumference in study group $(n=50)$

\section{Discussion}

In the present study, the values of waist circumference and body mass index in controls were almost within normal range and also similar to reported by the several investigators from abroad 2-8.

In this study, the value of waist circumference in hypertensive patient was higher than that of controls
Association of Obesity with Hypertension in Adult Female

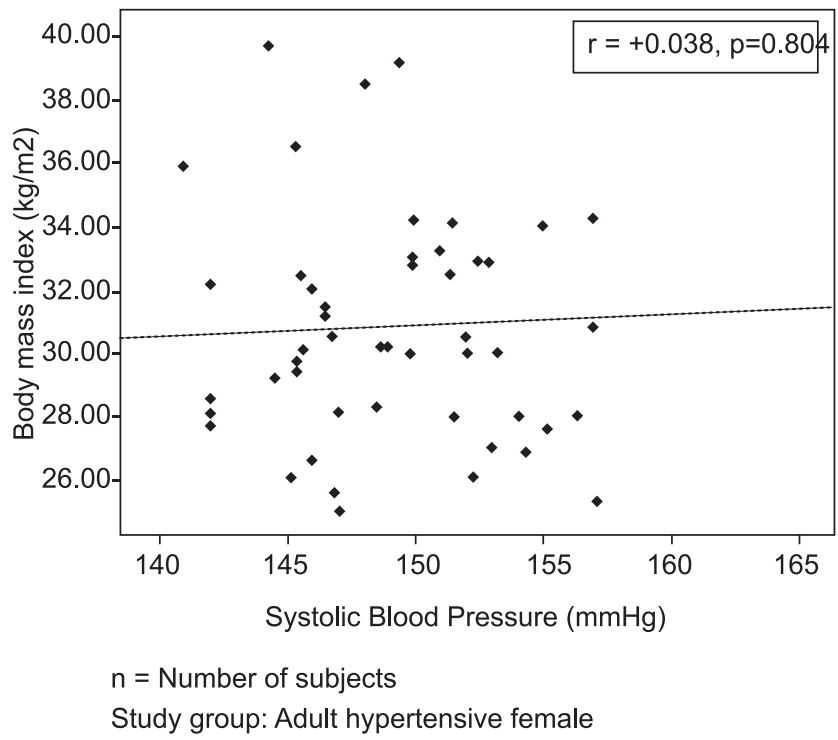

Fig.-2: Correlation between systolic blood pressure and body mass index in study group $(n=50)$

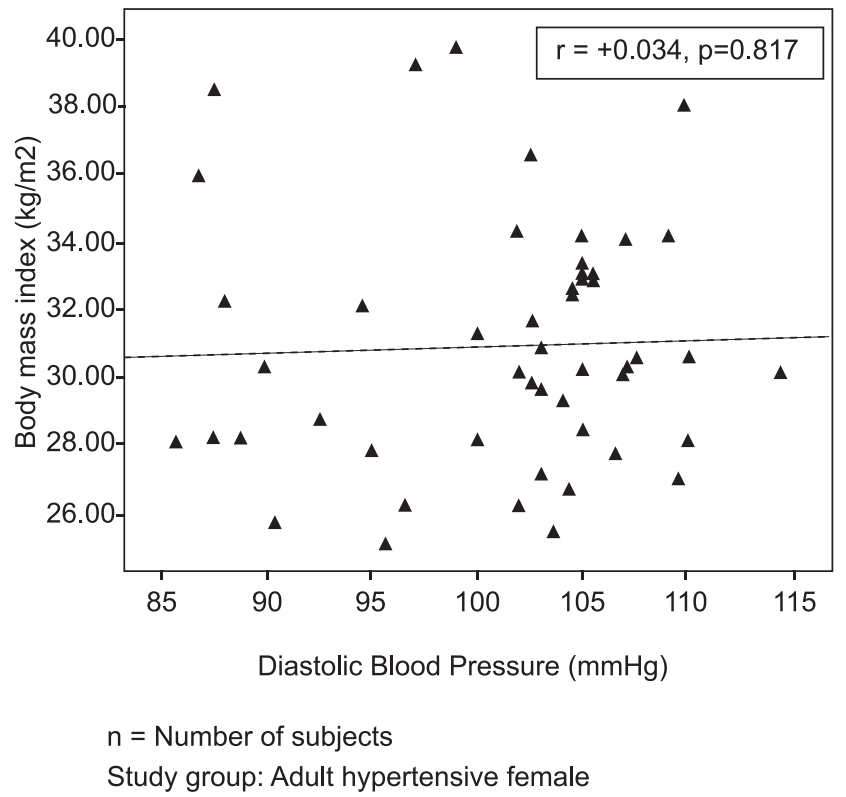

Fig.-4: Correlation between diastolic blood pressure and body mass index in study group $(n=50)$

and result was statistically -significant. Similar types of observations were found by other workers.

The body mass index in hypertensive subjects was higher than those of controls and result was statistically $(p<0.001)$ significant. Similar types of findings were reported by different researchers of different countries $2-8,13$. On the contrary, similar 
observations were made by other researchers but they did not find any significant difference in body mass index value between the groups. They suggested that it may be due to different type of nutrition and life style in their study population.17,

Again, correlation analysis showed positive correlation of systolic blood pressure with waist circumference and body mass index. In addition, diastolic blood pressure also showed positive correlation with waist circumference and body mass index. Similar observation was also reported by some investigators. 18 ,

Many explanations are suggested by different investigators regarding the development of obesity in hypertensive patient. It has been suggested that obesity is associated with increased blood flow, vasodilatation, cardiac output and hypertension. They suggested that obesity is associated with increase cardiac output and increase blood pressure in postmenopausal women due to additional blood flow for the extra adipose tissue. Again, blood flow in the heart, kidney, gastrointestinal tract and skeletal muscle also increases with weight gain due to increased metabolic rate and growth of the organs and tissues in response to their increased metabolic demands. ${ }^{18}$ In addition, in obese women due to increased sympathetic activity, renin secretion increases by kidney. Which in turn increases formation of angiotensin II, and it directly increase renal tubular reabsorption of sodium and stimulate synthesis of the sodium retaining hormone aldosterone. Similarly, obesity is associated with hyperinsulinemia. Because insulin can some circumstances produce enhanced tubular reabsorption of sodium and increases blood pressure. ${ }^{19}, 20$ Again, some researcher suggested that obesity is related with elaboration of adipokines (hormones produced in fat itself) such as leptin. These leptin again increase the blood pressure through sympathetic activation. ${ }^{21}$ Finally, structural changes in the kidney secondary to obesity seem to be important. The pressure of fat depots around the kidneys, coupled with increased abdominal pressure secondary to obesity, has been suggested as an additional cause of disordered renal sodium reabsorption. 22,23 Moreover, the hyper filtration observed in obesity sets the stage for progressive glomerular loss and loss of renal function and associated increase in blood pressure. 23

In the present study, both waist circumference and body mass index values are higher in hypertensive subject than that of controls. Furthermore, in the present study, waist circumference, body mass index, showed positive correlation with systolic and diastolic blood pressure in hypertensive patient. These finding supports the relationship between obesity and elevated blood pressure in hypertensive subject.. But exact mechanism is not elucidated by this type of study due to time and financial constraints.

\section{Conclusion}

From this study, it can be concluded that central obesity, which is characterized by higher values of waist circumference and body mass index may present in hypertensive subjects, may be due to obesity..

\section{Acknowledgement}

The authors are thankful to the study subjects for their active, sincere and voluntary participation. The authors are also grateful to the Department of Physiology for all kind of support.

\section{References}

1. Aki OA, Khairy AE, Abdel-Ai NM, Degheli Bs, Amer Zf. Knowledge, Attitude, Practice and Performance of Family Physicians Concerning Holistic Management of hypertension. J Egypt public Health Assoc. 2006; 81 (5): 337-53.

2. Who. Hypertension control. Technical Report Series No 862,Geneva: 3020.

3. Kearney PM, Whelton M,Reynolds K, Whelton PK. Global burden of hypertension: analysis of worldwide data. Lencet..2005; 365:217-223.

4. Theodire A. Kotchen.Obesity-related Hypertension? Hypertension.2008; 52:801-802.

5. Readinger, RN. The prevalence and etiology of non genetic obesity. SMJ. 2008;101(4):395-399.

6. World Health Organization:Global strategy on diet, physical activity and health.http://www.who.int/ diet.physicalactivity/publications/obesity/en/2010.

7. Julius S,Valentini M, Palatini P. Overweight and hypertension: a 2way street?.Hypertension;2000: 35:807-813.

8. Harlan WR,Hull AL, Schmouder RL Landis JR, Thompson FE Larkin. Blood pressure and nutrition in adults.The National Health and Nutrition Examination Survey. Am J Epidemiol.1984;120:1728.

9. Narkiewicz K. Obesity ana hypertension-the issue is more complex than we thought. Nephrol Dial Transplant.2006; 21:264-267

10. Aneja A,EL-Atat F,Mc Fariane Si Sowera JR. Hypertension and obesity.Recent progress in hormone Reasearch 2004; 59: 169-205.

11. The global Challege of obesity and the international Obesity Task Force. Who classification of obesity, http/www.juns. org/features/obesity/tabfig.htm. 12. Narkiewicz K. Obesity ana hypertension-the issue is more complex than we thought. Nephrol Dial Transplant.2006; 21:264-267 
BJM Vol. 28 No. 1

13. Richard N. Re, MD. Obesity -related hypertension.The Ochsner J.2009;9:133-136

14. Deepa R, Shanthi rani CS. Prevention of insulin resistance system in a selected south Indian population,Chenni. Indian J Med Res.2000;115: 198-27.

15. Chobanian AV, Bakris GL, Black HR, Cushan WC, Green LALzzo JL.The seventh Report of the Joint National Committee on Prevention, Detection, JNC 7 report. JAMA. 2003;289:2560-2572.

16. Garrison RJ, Kannel WB, Stokes J. Incidence and ptrcursors of hypertension in young adults. The Framingham offspring study. Preventive medicine.1987; 16:235-251.

17. Shu-Kang Wang, Wei Ma, Shumei Wang, Xiang-Ren Yi, Hong-Ying Jia. Obesity and its relationship with Hypertension among Adult 50 years and Older in Jian, China.PLOS ONE.2014; 9(12):1-10.
Association of Obesity with Hypertension in Adult Female

18. Guyton,AC, Hall, JE.Text Book of Medical Physiology. $11^{\text {th }}$ ed. SB Saunders, Mississipi.

19. Sarzani R, Salvi F, Dessi- Fulgheri P, Rappelli A. Renin-angiotensin system, natriuretic peptides, obesity, metabolic syndrome and hypertension: an integrated view in human. J Hypertenss. 2008; 26(5): 831-843.

20. Bloomgarden ZT. Obesity, hypertension and insulin resistance. Diabetes Care. 2002; 25(11): 2088-2097.

21. Wofford MR, Hall JE. Pathophysiology and treatment of obesity, hypertension..Curr Pham Des.2004; 10(29): 3621-3637.

22. Hall JE. Pathophysiology of obesity hypertension. Curr Hypertens Rep.2000;2(2): 139-147.

23. Hall JE, Crook ED, Jones DW, Wofford MR, Dubbert PM. Mechanisms of obesity-associated cardiovascular and renal disease. Am J Med Sci. 2002;324(3): 127-137. 